\title{
Rainfall Rate Duration Study for Performance Assessment of Satellite Communication Links
}

\author{
Jorge L. Cerqueira ${ }^{1}$ and Mauro S. Assis ${ }^{2}$ \\ ${ }^{1}$ Military Institute of Engineering, Praça General Tibúrcio 80, 22290-270 Rio de Janeiro, RJ, Brazil \\ ${ }^{2}$ Brazilian Committee of URSI, Rua Coelho Neto 17, Apartment 301, 22231-110 Rio de Janeiro, RJ, Brazil
}

Correspondence should be addressed to Mauro S. Assis; msassis@openlink.com.br

Received 14 March 2013; Accepted 19 April 2013

Academic Editor: Giampiero Lovat

Copyright ( 2013 J. L. Cerqueira and M. S. Assis. This is an open access article distributed under the Creative Commons Attribution License, which permits unrestricted use, distribution, and reproduction in any medium, provided the original work is properly cited.

\begin{abstract}
The duration of rainfall events as a function of precipitation rate is investigated in this paper. The experimental data used in this study were measured along a rain gauge network with 8 pluviographs located in the Amazon region. The most important point to be highlighted in this study is the evidence of a correlation between rain and fade events durations observed in a $12 \mathrm{GHz}$ satellite link. This result is quite important under the engineering point of view, once it can be used in the design of improvement techniques for low availability satellite systems.
\end{abstract}

\section{Introduction}

In the planning of low availability satellite systems, an outage of $1 \%$ to $0.1 \%$ in the worst month is normally acceptable. In these systems the temporal variability of fading has a strong impact on system design. Consequently, the knowledge of rain dynamics is of fundamental relevance. It is recognized that the conversion of rain rate duration to slant path duration statistics is not an easy task [1]. The main problems are the vertical nonhomogeneity of rain structure and the possibility of having more than one rain cell along the propagation path. However, according to Timothy et al. [2], if the vertical distribution of rain is uniform from the earth surface to a height near the $0^{\circ}$ isotherm level and the elevation angle is higher than $30^{\circ}$, the measured rainfall rate threshold at a given probability level may be used to obtain information on the dynamics associated with the attenuation in slant path. A study by Lekkla and Prapinmongkolkarn [3] corroborates this assertion. In this context, based on measurements carried out in the Brazilian Amazon region, this paper investigates the duration of rainfall events as a function of precipitation rate. Figure 1 shows the rain gauge network used in the study described here and details about these sites are presented in Table 1.

\section{Rainfall Rate Events Duration Statistics}

In each site shown in Figure 1, measurements of rain duration were carried out for a total period of one year between 2003 and 2005. The integration time of precipitation rate was 10 s to be near the instantaneous value and more adequate to be aligned with the dynamics of signal attenuation. An example of rain duration statistics for the 8 sites illustrated in Figure 1 and a rain rate threshold of $50 \mathrm{~mm} / \mathrm{h}$ is depicted in Figure 2 . It is noted that, with only one exception, all the other sites have shown the same behaviour. The exception was in the site of Cruzeiro do Sul $\left[7^{\circ} 36^{\prime} \mathrm{S} ; 72^{\circ} 40^{\prime} \mathrm{W}\right]$ where a large number of fast events were observed, mainly around 10 seconds. If those events were taken out from the analysis, this site would present a variation similar to the others. Additionally, any aspect capable of connecting one distribution to a climatic subtype in the Amazon region was not identified. In reality, there was a mix of all distributions, although, according to Köppen [4], there are 3 climatic subtypes (rainy equatorial, monsoon tropical, and wet-and-dry tropical) in this region. On the other hand, excepting the site of Cruzeiro do Sul, for probability levels higher than $0.1(10 \%)$, the variation between each distribution and the median distribution is lesser than $15 \%$. 
TABLE 1: Description of the experimental sites.

\begin{tabular}{|c|c|c|c|c|}
\hline Site & Latitude & Longitude & Period of measurements & Uptime \\
\hline Belém & $1^{\circ} 23^{\prime} \mathrm{S}$ & $48^{\circ} 26^{\prime} \mathrm{W}$ & $09 / 2003-08 / 2004$ & $97,4 \%$ \\
\hline Boa Vista & $2^{\circ} 47^{\prime} \mathrm{N}$ & $60^{\circ} 41^{\prime} \mathrm{W}$ & $04 / 2004-03 / 2005$ & $100 \%$ \\
\hline Cruzeiro do Sul & $7^{\circ} 36^{\prime} \mathrm{S}$ & $72^{\circ} 40^{\prime} \mathrm{W}$ & 02/2004-01/2005 & $100 \%$ \\
\hline Macapá & $0^{\circ} 02^{\prime} \mathrm{N}$ & $51^{\circ} 05^{\prime} \mathrm{W}$ & $11 / 2003-10 / 2004$ & $100 \%$ \\
\hline Manaus & $3^{\circ} 05^{\prime} \mathrm{S}$ & $60^{\circ} 04^{\prime} \mathrm{W}$ & 04/2004-03/2005 & $96,2 \%$ \\
\hline Santarém & $2^{\circ} 30^{\prime} \mathrm{S}$ & $54^{\circ} 43^{\prime} \mathrm{W}$ & 09/2003-08/2004 & $92,7 \%$ \\
\hline São Gabriel da Cachoeira & $0^{\circ} 07^{\prime} \mathrm{S}$ & $67^{\circ} 04^{\prime} \mathrm{W}$ & $09 / 2003-08 / 2004$ & $82 \%$ \\
\hline Tabatinga & $4^{\circ} 14^{\prime} \mathrm{S}$ & $69^{\circ} 56^{\prime} \mathrm{W}$ & 05/2004-04/2005 & $96,7 \%$ \\
\hline
\end{tabular}

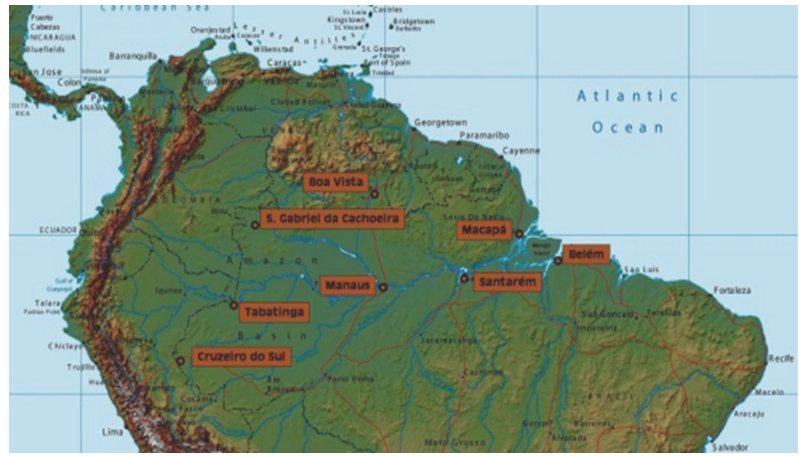

FIGURE 1: Rain gauge network.

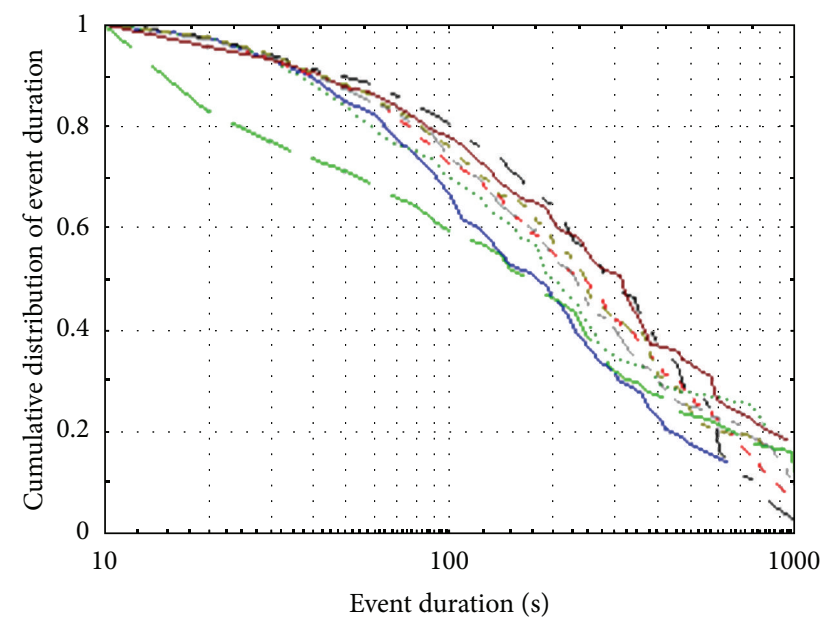

FIgURE 2: Rainfall rate duration distributions.

Based on this result, it can be concluded that in a given region with the same climatic characteristics the dynamic behaviour does not present significant variability. In other words, the statistics of rainfall rate duration are basically invariant within the same climatic region. The same conclusion was also reported by Goldhirsh [5] and Coma et al. [6].

This paper has adopted the Weibull function of two variables for modeling the rainfall rate duration. This function has the following mathematical form:

$$
P\left(D \geq D_{0}\right)=\exp \left[-\left(\frac{D_{0}}{\eta}\right)^{\alpha}\right],
$$

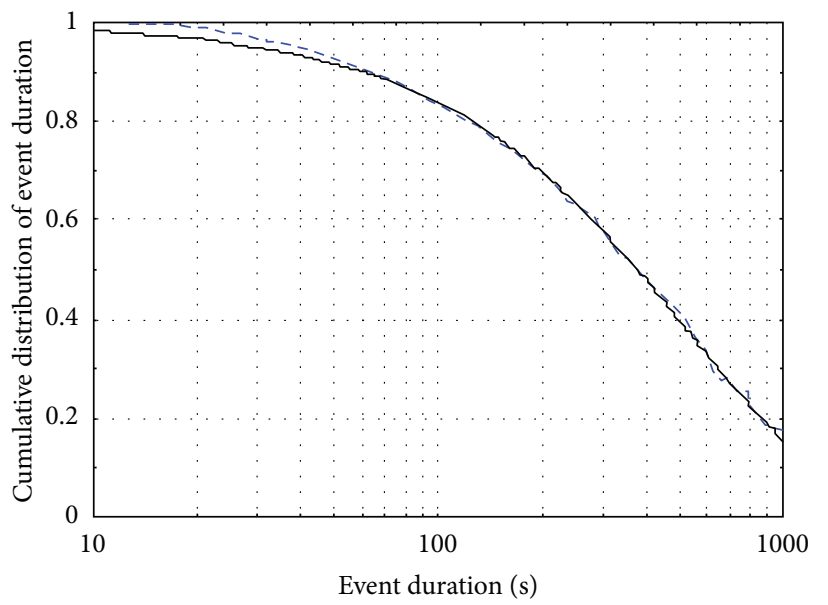

FIGURE 3: Comparison between the Weibull function (full line) with experimental data from Belém (broken line) for $30 \mathrm{~mm} / \mathrm{h}$.

where $D$ is the event duration and $D_{0}$ the duration taken as reference.

Besides its simplicity, this function has been employed in the analysis of fade duration in equatorial and tropical regions [7, 8]. All the curves in Figure 2 were adjusted according to (1) with a mean correlation higher than $95 \%$. For instance, Figure 3 shows the comparison between the cumulative distribution of rain duration measured in Belém $\left[1^{\circ} 23^{\prime} \mathrm{S} ; 48^{\circ} 26^{\prime} \mathrm{W}\right]$ for a precipitation threshold of $30 \mathrm{~mm} / \mathrm{h}$ with the corresponding Weibull distribution. The values of $\alpha$ and $\eta$ were 1.02 and 539.6, respectively. A very good agreement was observed.

On the other hand, it is possible to adjust a power function to the event duration as a function of the precipitation rate and the percentage of time where this rate is exceeded. This power function is given by

$$
D=a(p) R^{-b(p)},
$$

where $a$ and $b$ are variables depending on the considered percentage.

Expression (2) has allowed a satisfactory adjustment of event duration for percentages between 5\% and 95\%. An example is given in Figure 4 for the site of Belém, where the integration time of precipitation rate was one minute. 


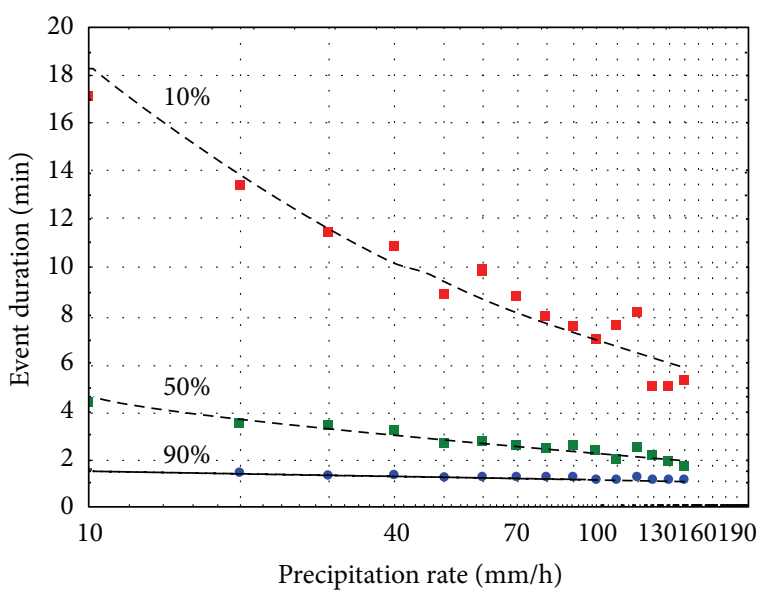

FIgURE 4: Precipitation rate duration versus precipitation rate threshold at equal probability levels compared with the empirical model given by expression (2).

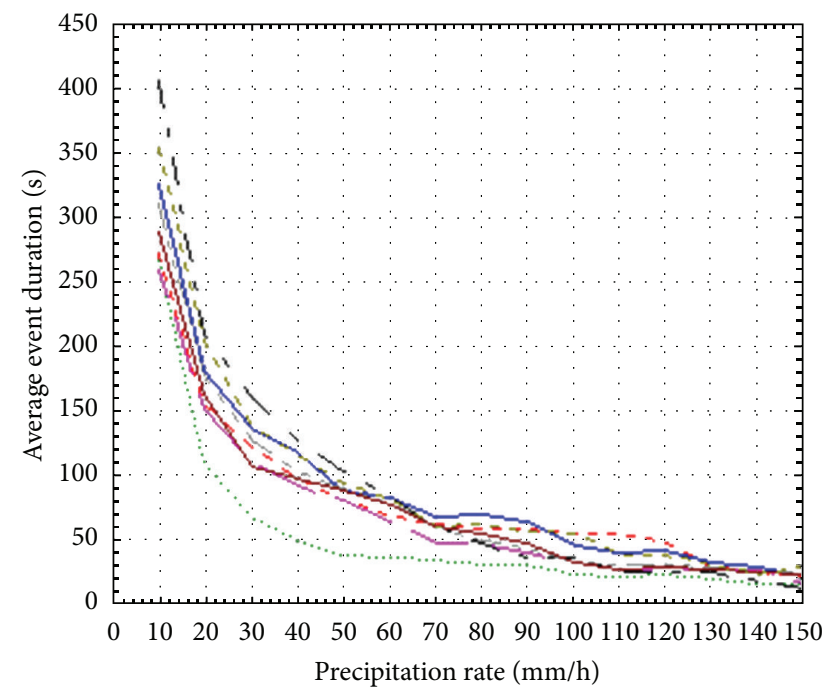

FIGURE 5: Average rain duration as a function of precipitation rate.

\section{Average Event Duration}

Figure 5 shows the average event duration as a function of the precipitation rate for all sites depicted in Figure 1. Once more, excepting the site of Cruzeiro do Sul, all the others have presented a similar behaviour. As commented previously, the planning of low availability satellite systems taken as reference rain rates exceeded between $1 \%$ and $0.1 \%$ of the worst month. Measurements in the Amazon region [9] show that these percentages correspond to precipitation rates between 20 and $90 \mathrm{~mm} / \mathrm{h}$. Consequently, the average event duration of interest for designing improvements techniques to satellite systems is around 1 and 3 minutes. This result is in accordance with the $12.75 \mathrm{GHz}$ rain attenuation measurements carried out by Pan and Allnutt [10] using satellite beacon and radiometers in Lae, Papua New Guinea $\left(7^{\circ} \mathrm{S}\right.$ and $\left.147^{\circ}\right)$.

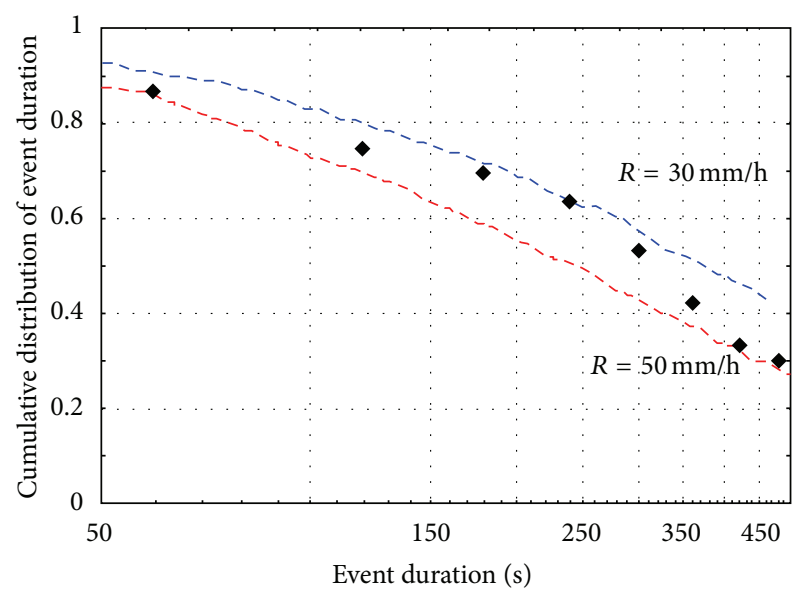

FIgure 6: Comparison between the durations of rain and fade events.

\section{Comparison between Rain and Fade Event Durations}

Based on measurements carried out in Belém, Figure 6 shows the evidence of correlation between the durations of rain and fade events. The curves in this figure correspond to precipitation rates exceeded for 30 and $50 \mathrm{~mm} / \mathrm{h}$, respectively (broken lines). The isolated points are referred to fade durations higher than $7 \mathrm{~dB}$ [11] observed in a $12 \mathrm{GHz}$ beacon receiver located also in the area of Belém. It is clear that the events of fade duration are well in agreement with the rain events.

\section{Concluding Remarks}

Based on measurements carried out in a rain gauge network with 8 pluviographs, this paper has investigated the problem of precipitation event duration in the Amazon region. The experimental data have allowed the analysis of the following items: (a) the statistical behaviour of the rain event duration; (b) the use of the two-variable Weibull function as mathematical model to characterize such events; (c) The mathematical representation, by a power function, of the rain event duration in terms of the precipitation rate and the time percentage that this precipitation is exceeded; (d) The average event duration of interest for designing fade countermeasures (e.g., adaptive FEC and/or modulation techniques, uplink power control, etc.) for satellite systems; (e) the evidence of a correlation between the durations of rain and fade events. Under the practical point of view, it should be emphasized that the material presented here are quite relevant for planning low availability satellite systems in $\mathrm{Ku}$ and $\mathrm{Ka}$ bands in equatorial regions.

\section{References}

[1] J. Allnutt and F. Haidara, "Ku-Band duration data from three, two-year, earth-space experiments in equatorial Africa," in Proceedings of the URSI Commission F Open Symposium Climatic 
Parameters in Radiowave Propagation Prediction (CLIMPARA '98), pp. 163-166, Ottawa, Canada, April 1998.

[2] K. I. Timothy, N. C. Mondal, and S. K. Sarkar, "Dynamical properties of rainfall for performance assessment of earth/space communication links at Ku and Ka bands," International Journal of Satellite Communications, vol. 16, no. 1, pp. 53-57, 1996.

[3] R. Lekkla and P. Prapinmongkolkarn, "Diurnal variations in rain attenuation on $\mathrm{Ku}$ band earth-space paths," International Journal of Satellite Communications, vol. 16, no. 5, pp. 219-236, 1998.

[4] H. Critchfield, General Climatology, Prentice Hall, New Jersey, NJ, USA, 3rd edition, 1974.

[5] J. Goldhirsh, "Rain-rate duration statistics over a five-year period: a tool for assessing slant path fade durations," IEEE Transactions on Antennas and Propagation, vol. 43, no. 5, pp. 435-439, 1995.

[6] J. Coma, F. Ghaloul, and A. Benarroch, "Statistics of rain rate variability for Spanish regions: the durations of excedances," in Proceedings of the URSI Commission F Open Symposium Climatic Parameters in Radiowave Propagation Prediction (CLIMPARA '98), pp. 62-65, Ottawa, Canada, April 1998.

[7] E. Ofoche, "Duration of tropical rainfall rate for predicting radiowave attenuation," in Proceedings of the URSI Commission F Open Symposium Climatic Parameters in Radiowave Propagation Prediction (CLIMPARA '90), pp. 56-61, Rio de Janeiro, Brazil, December 1990.

[8] E. Couto de Miranda, R. Sousa, and L. Silva Mello, "Dynamic analysis of attenuation on five converging links at $15 \mathrm{GHz}$ located in the great Sao Paulo Area, Brazil," in Proceedings of the 10th International Conference on Antennas and Propagation, pp. 14-17, Edimburgo, UK, April 1997.

[9] J. L. Cerqueira, M. S. Assis, and L. Silva Mello, "Rain attenuation research in Brazil," in Proceedings of the 28th URSI General Assembly, New Delhi, India, October 2005.

[10] Q. W. Pan and J. E. Allnutt, "12-GHz fade durations and intervals in the tropics," IEEE Transactions on Antennas and Propagation, vol. 52, no. 3, pp. 693-701, 2004.

[11] ITU-R, "Dynamic statistics of slant path attenuation in Brazil", WP 3J 3J/75, ITU-R recommendations, Geneva, Switzerland, 2004. 

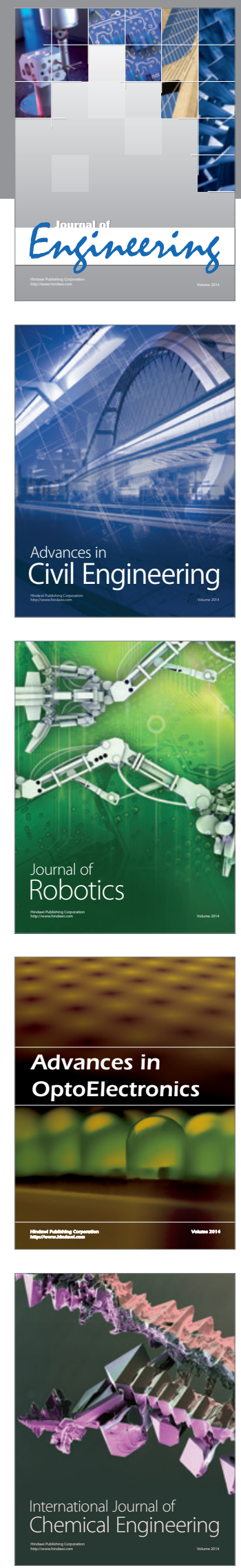

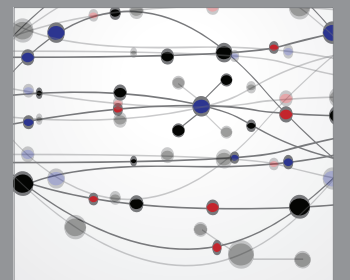

The Scientific World Journal
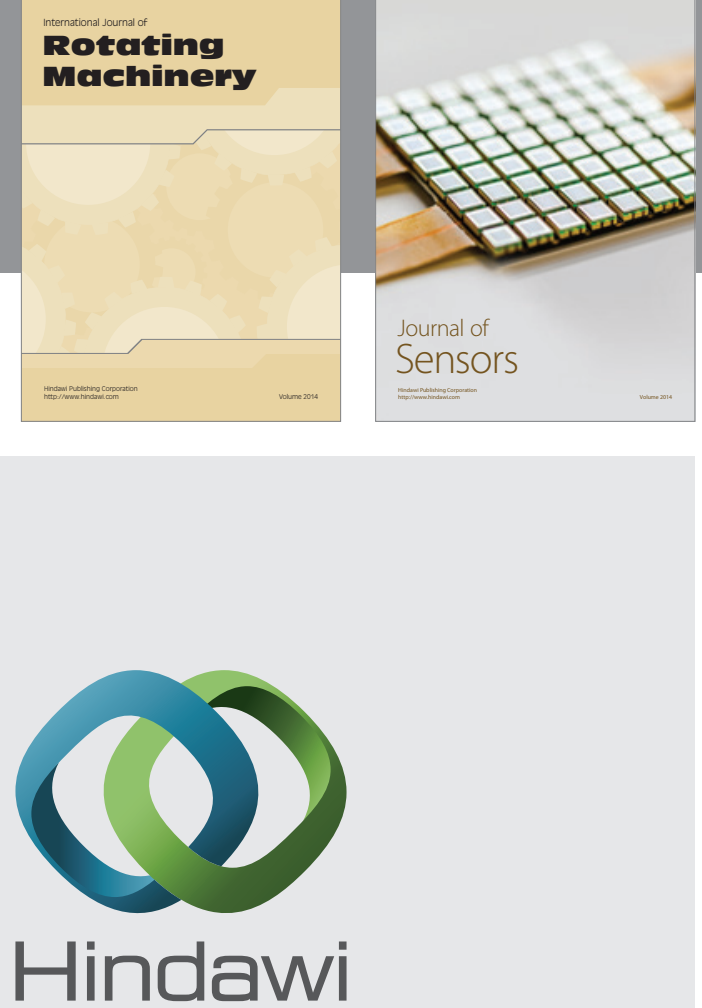

Submit your manuscripts at http://www.hindawi.com
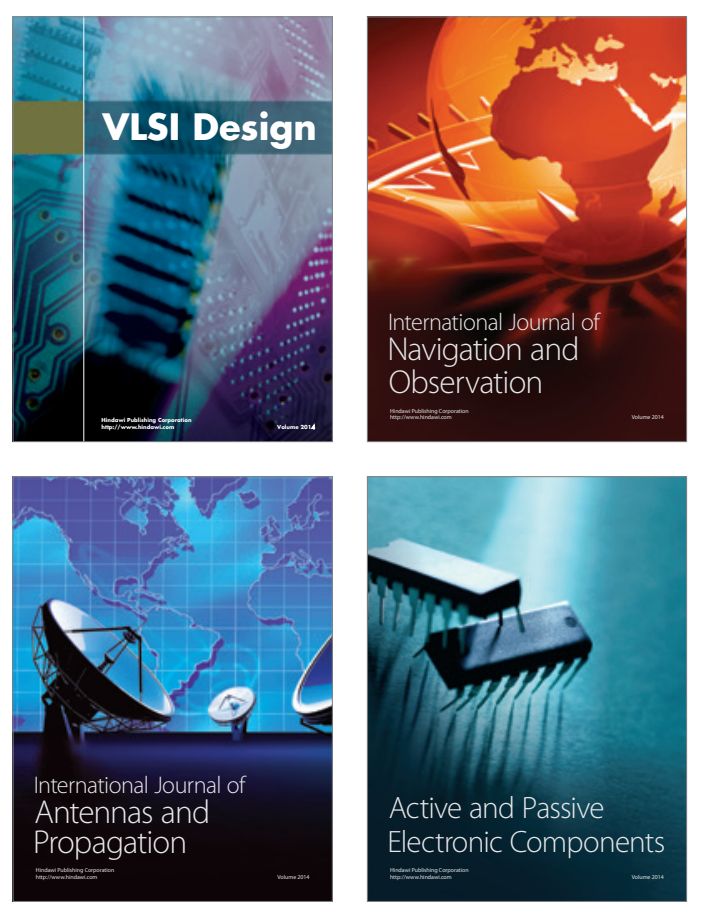
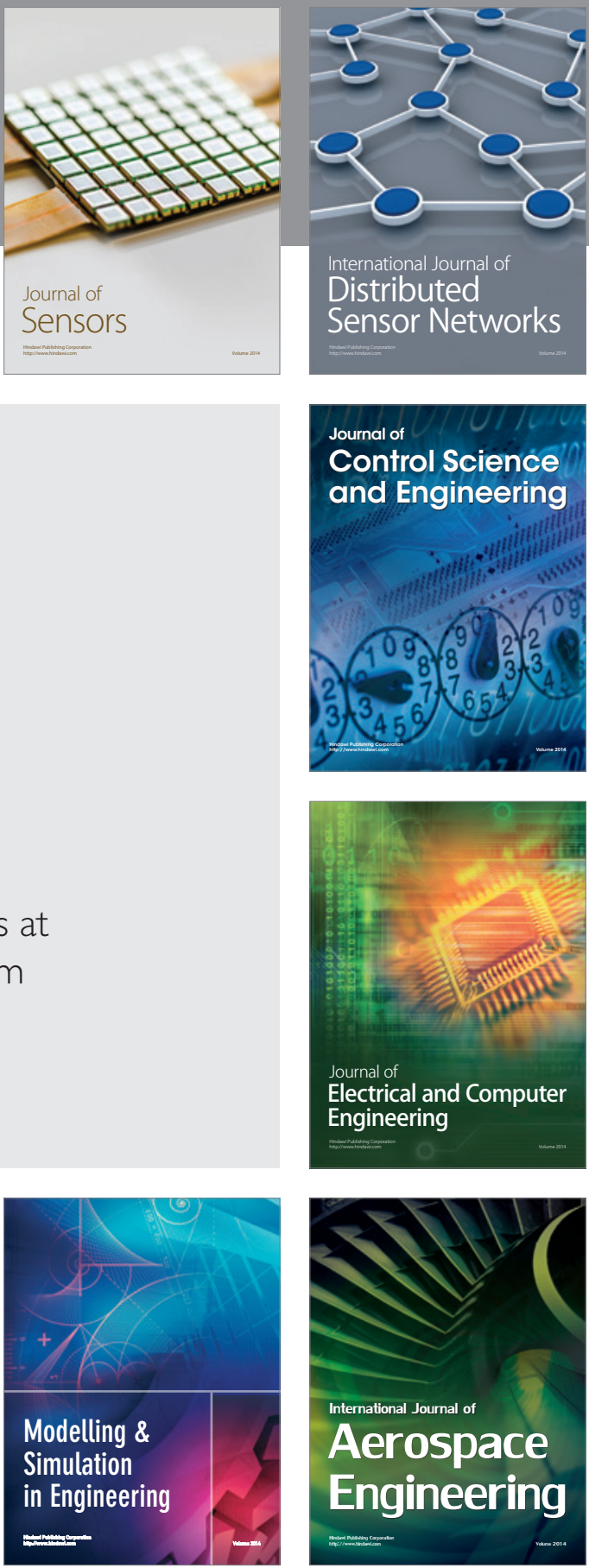

Journal of

Control Science

and Engineering
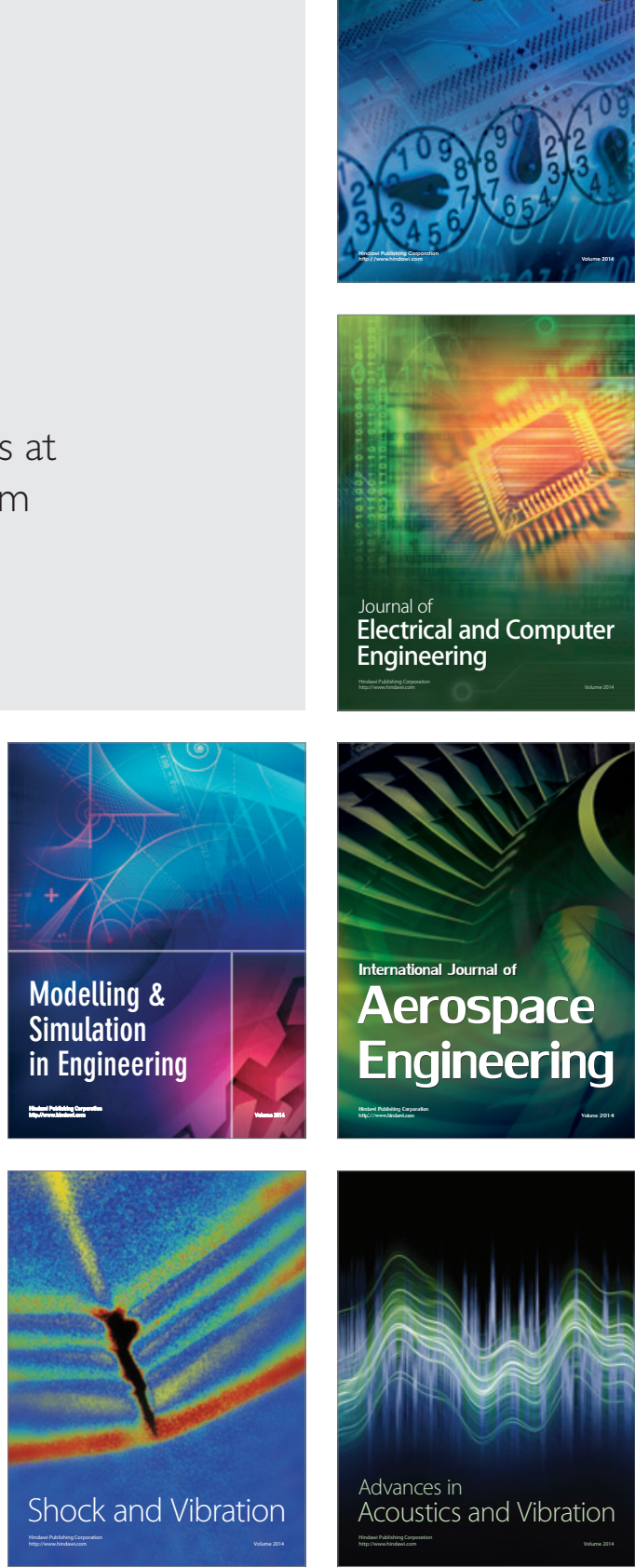